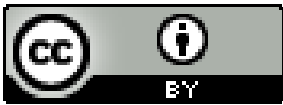

\title{
COMO MATAR LENTAMENTE A SI MESMO E CONTINUAR
}

\section{VIVENDO?}

Alan Ribeiro $^{l}$

Resumo: Neste ensaio, apresento uma reflexão sobre como homens negros inscrevem de modo complexo suas maneiras de expressão de sentimentos e afetos como discursividades sobre o Eu. Discuto a noção de solidão atrelada aos debates sobre assimetrias relativas a dinâmicas que envolvem relacionamentos afetivo-sexuais e sugiro uma ampliação de seu uso para outras modalidades de interação e de percepção das narrativas sobre emocionalidades. Discorro sobre maneiras de pensar estas narrativas sobre si entre homens negros fora da dicotomia poder e não-poder e indico uma maneira de falar sobre a solidão como um elemento constitutivo das relações. Discuto o uso do termo solidão como sinônimo de isolamento social e estipulo, a partir de uma imagem religiosa, um lugar para pensar como devemos resistir aos mecanismos de isolamento social e afetivo vividos em contextos de crise de relacionamentos, seja os relacionamentos afetivo-sexuais, seja os relacionamentos político-sociais existentes na esfera pública.

Palavras-chave: masculinidades; raça; política; emoções; solidão

\section{HOW TO SLOWLY KILL YOURSELF AND KEEP ON LIVING?}

Abstract: In this essay, presents a reflection on how black men complexly inscribe their ways of expressing feelings and affections as discursivities about the self, expanding its use to other modalities of interaction and perception of narratives about emotionalities. Discusses ways of thinking about these narratives about themselves among black men outside the power and non-power dichotomy and point to a way of talking about loneliness as a constitutive element of relationships. Speaks the use of the term loneliness as a synonym for social isolation and stipulation, from a religious image, a place to think about how we should resist the mechanisms of social and emotional

\footnotetext{
${ }^{1}$ Professor Adjunto A2 do Instituto de Ciências da Educação, da Universidade Federal do Oeste do Pará (ICED-UFOPA). Doutor em Educação, linha de pesquisa Sociologia da Educação, no Programa de PósGraduação em Educação da Universidade de São Paulo (PPGE-USP). Mestre em Ciências Sociais, Antropologia, pelo Programa de Pós-Graduação em Sociologia e Antropologia (PPGSA-UFPA). Visitor Graduate Student at Department of Africana Studies, Brown University (EUA). Pesquisa raça, classe, gênero/masculinidades, sociabilidade juvenil, educação escolar quilombola, desempenho escolar, relações étnico-raciais para a educação escolar. Líder do Grupo de Estudos e Pesquisas Raça, Educação e Etnicidades na Amazônia (GEREA). Integrante colaborador do Grupo de Estudos e Pesquisas EDGES (USP). Integrante colaborador do Grupo de Estudos HiISTEDBR (UFOPA). E-mail: alan.ribeiro@,ufopa.edu.br
} 
isolation experienced in relationship crisis contexts, be it affective-sexual relationships, be the political-social relationships existing in the public sphere.

Keywords: masculinities; race; politics; emotions; loneliness

\section{¿CÓMO MATARTE LENTAMENTE Y SEGUIR VIVIENDO?}

Resumen: En este ensayo, presento una reflexión sobre cómo los hombres negros inscriben de manera compleja sus formas de expresar sentimientos y afectos como discursividades sobre el Ser. Discuto la noción de soledad vinculada a los debates sobre las asimetrías sobre dinámicas que involucran relaciones afectivo-sexuales y sugiero una ampliando su uso a otras modalidades de interacción y percepción de narrativas sobre emocionalidades. Discuto formas de pensar acerca de estas narraciones sobre ellos mismos entre hombres negros fuera de la dicotomía entre el poder y el no poder y señalo una forma de hablar de la soledad como un elemento constitutivo de las relaciones. Discuto el uso del término soledad como sinónimo de aislamiento social y hago una estipulación, desde una imagen religiosa, acerca de un lugar para pensar cómo debemos resistir los mecanismos de aislamiento social y afectivo experimentados en contextos de crisis de relación, ya sean relaciones afectivo-sexuales, ser las relaciones político-sociales existentes en la esfera pública.

Palabras clave: masculinidades; raza; política; emociones; soledad

\section{COMMENT SE TUER LENTEMENT ET CONTINUER À VIVRE?}

Sommaire: Dans cet article, je présente une réflexion sur la manière dont les hommes noirs inscrivent de manière complexe leurs manières d'exprimer des sentiments et des affects en tant que discursivités à l'égard du Soi, en abordant la notion de solitude liée aux débats sur les asymétries concernant les dynamiques impliquant des relations affectives sexuelles. étendre son utilisation à d'autres modalités d'interaction et de perception des récits sur les émotions. Je discute des façons de penser ces récits sur euxmêmes parmi des hommes noirs en dehors de la dichotomie pouvoir et non pouvoir, et suggère une façon de parler de la solitude en tant qu'élément constitutif des relations. Je discute de l'utilisation du terme solitude comme synonyme d'isolement social et de stipulation, à partir d'une image religieuse, d'un lieu de réflexion sur la manière dont nous devrions résister aux mécanismes d'isolement social et affectif vécus dans les contextes de crise relationnelle, qu'il s'agisse de relations affectives ou sexuelles, être les relations politiques et sociales existant dans la sphère publique.

Mots-clés: masculinités - race - politique - émotions - solitude

Para J. Cacioppo e W. Patrick (2010), a vivência do que ele chama de solidão afetiva e emocional envolve pelo menos quatro aspectos: sentimentos paradoxais, emoções contraditórias, escolhas relacionais marcadas por interesses arbitrários e ações 
direcionadas egoicamente. Estes diferentes aspectos aparecem neste livro para discutir a relação definida como "complexa e obscura" entre desejos, emoções e afetos em diferentes modalidades de relacionamentos sociais. Esta solidão afetiva e emocional é apresentada por Ana Pacheco (2013) a partir de relatos de diferentes mulheres negras. A partir destas experiências individuais, a solidão da mulher negra passou a denunciar a preterição marital no campo das escolhas afetivo-sexuais, apresentando trajetórias individuais marcadas pelo isolamento social em diferentes espaços e grupos sócioraciais.

No presente ensaio, procuro construir uma reflexão sobre distintos aspectos relacionados ao tema da solidão com o objetivo de realizar certos apontamentos sobre o lugar dos homens negros cisheterossexuais e suas masculinidades racializadas nesta lógica da vivência da solidão afetiva e emocional. Em outras palavras, quero ressaltar diferentes posicionalidades que tecem subjetividades ambivalentes como partes do cuidado de si e para si, como parte da percepção do Eu. Quero pensar também como estas posicionalidades estão articuladas com performances emocionais e com uma certa "política dos afetos" que talvez apareça nas maneiras como diferentes homens negros experienciam a racialização de suas subjetividades em diferentes relações e contextos sócio-raciais.

Para tanto, a primeira estratégia intelectual consiste em separar, a díade "paradoxo e contradição" do binômio "interesse e direcionamento “. A primeira díade fez com que eu pensasse em como há uma demanda crescente de autonomia e autocentramento na modernidade que se confunde com certas exigências por um domínio sobre si, isto é, uma suposta super-capacidade de conduzirmos - e controlarmos nossas emocionalidades diante das interações complexas nas quais socialmente estamos inseridos, sendo totalmente influenciados por elas. Esta primeira díade parece, por um lado, cobrar um "auto-controle total" sobre nossos sentimentos que supostamente nos torna insuscetível às interações humanas. Por outro lado, quando este "auto-controle total" não é executado individualmente, ele se apresenta como fragilidade emocional, como fraqueza moral entre homens negros, de modo que a vontade de poder controlar os modos pelos quais sentimos o que sentimos, de poder manipular o que, como e quem desejamos e direcionar os nossos afetos passa a ser, de certo modo, resultado de uma dita escolha unilateral, não o resultado de uma interação, não o resultado de uma 
relação. Estas primeiras dimensões da afetuosidade e da emocionalidade estariam, deste modo, fora de nosso domínio individual, estariam além da escolha auto-consciente, sendo, por assim dizer, estruturais.

As duas outras palavras, o binômio do interesse e do direcionamento de nossas ações, fizeram com que eu pensasse que nossos desejos, emoções e afetos não estariam fora do alcance de nossa consciência, não seriam um produto para si. De outro modo, elas se situariam dentro de um conjunto de relações vividas que nos fazem acreditar que é possível conduzir e decifrar de modo auto-consciente nossos desejos, emocionalidades e afetuosidades como se fossem forças manipuláveis e totalmente discerníveis pela vontade individual. De acordo com esta segunda díade, estipulei esperançosamente que se poderia pensar em uma autonomia do sujeito que o faz reaparecer como um ser livre e atuante sobre os próprios sentimentos. Notei, porém, que esta leitura dicotômica é uma armadilha: paradoxo, contradição, direcionamento e interesse devem ser vistos mais como elementos correlacionados do que como duplas de opostos, mais como constituintes de uma totalidade complexa que não nos comprime e não foge de nós, do que como forças que não se submetem, que não estão sob nosso controle, que não regulam nossas maneiras de sentir. Em resumo: não mandam e não obedecem, mas mandam e obedecem. Quando usamos um Eu pensante, quando evocamos um lugar de fala, é importante localizar a posicionalidade de nossa fala para não confundirmos a representação de experiências coletivas como uma apresentação de um Eu social.

Nos últimos 20 anos, a construção de um nós racial pensante, para usar uma ideia inspirada na nocão do eu racial pensante sobre o qual fala Paul Gilroy (2001) ao se remeter aos discursos sobre subjetividades negras na diáspora, omitiu um conjunto de contradições que recentemente passaram a figurar dentro do debate público sobre as modalidades de coletividade negra que se construiu retoricamente. É necessário iniciar um processo de desvelamento sobre estas modalidades de coletividade negra em alguns destes Nós, suscitando suas vantagens e desvantagens cognitivas. "Nós negros" ou "nós homens negros" são retóricas que ajudam em algumas coisas, mas nos iludem em outras, explicam certos processos, mas escondem outros. Ora, vamos pensar em um seguinte exemplo: um homem negro pobre, com 7 irmãos homens negros pobres e vários amigos homens negros pobres, que tem acesso à universidade e aos discursos sobre política racial passa a ser o único homem negro pobre do seu bairro que tem 
acesso à um conjunto de discursos e narrativas analíticas que o permitem manipular, diante de uma elite formalmente intelectualizada e informada politicamente, este "nós", possibilitando ilações como "nós somos", "nós queremos", "nós sentimos", "nós desejamos". Este homem negro, perante outros homens negros e mulheres negras, homens brancos e mulheres brancas das classes populares vivencia emocionalidades e afetuosidades sobre as quais pouco discutimos, uma vez que tendemos a localizar emoções e afetos nas esferas dos relacionamentos afetivo-sexuais, na esfera da sexualidade.

De fato, foi diante de outros homens negros que muitos de nós iniciamos processos de comparação acerca de nossas personalidades, de percepção sobre si e descobertas individuais de quem somos, a aprendizagens sobre admiramos, amamos e não amamos. Foi ao lado de outros homens, a maioria negros, olhando e escutando o que diziam para outros homens, muitos deles também negros, em espaços como mesas de bar, estádios de futebol, conversas entre amigos em espaços distintos de sociabilidade, festas de famílias, etc, que iniciamos uma jornada de percepção sobre o que, pelo menos normativamente, é ser um homem, um homem negro.

Neste ponto retorno ao enigma das quatro palavras. Sei que muitos de nós vivemos e sentimos esta relação complexa e obscura, ao mesmo tempo em que sonhamos por um "amor com a nossa cor". A ansiedade por um "amor afrocentrado" que possa reconstituir a "família negra" parece ser mais um regramento moral do que um projeto societal que nos impede de ver que estamos buscando algo que já existe, mesmo que fora dos moldes ideológicos trazidos pelo ativismo político negro. Muitos vínculos afetivo-sexuais "com a nossa cor" têm se sustentado entre muitos de nós, enfrentanto a pobreza, a miséria e as dificuldades impostas à pessoas negras e pobres quando tentam manter suas famílias vivas, seus filhos e netos homens negros vivos.

Sou de uma família extensa com muitos relacionamentos afetivo-sexuais entre homens negros e mulheres negras que estão juntos há quinze, vinte, trinta anos e posso argumentar, pelo menos de modo solipsita que o nosso problema não são relações que não existem, mas a qualidade das relações que existem. Alguns destes relacionamentos não são saudáveis, quase abusivos. Porém, os esforços cotidianos e os acordos que cada sujeito destes relacionamentos fez e refaz para ressignificar a relação e mantê-la existindo é dificilmente ponderável, e com muita dificuldade será compreendida se 
usarmos o léxico político que circula em mídias virtuais, em espaços de debates intelectualizados, em ambientes de sociabilidade voltados para pessoas negras e em circuitos de discussão política racial.

Certos discursos que circulam no debate público brasileiro têm contrabandeado discursivamente experiências individuais como se fossem coletivas e interpretado experiências coletivas como se fossem individuais. Esta metalepsia, isto é, a transformação da causa em consequência e da consequëncia em causa, para usar uma ideia de G. Spivak (2010), apresenta o vivido individual, seja de um youtuber negro, seja de uma blogueira negra, seja de um ativista negro universitário ou uma pessoa negra falando sobe si mesma, como se fosse manifestação direta da realidade vivida de um complexo e heterogênero coletivo negro. Este ou esta falante deve saber de que coletivo, de que "nós" deste coletivo está falando. É preciso desfazer este "nó" malfeito no qual quem fala se autoriza a falar por alguma coletividade sem ser autorizado por ela.

Não é todo mundo que acredita que processos psicossociais, conflitos simbólicos e políticas relacionais presentes em sistemas de opressão raciais, sexuais, de gênero e de classe incidem nesta relação entre desejos, emoções e afetos e fazem com que muitos de nós, homens negros, não consigam lidar normativamente com valores como ternura, docilidade e carinho, dificultando renúncias e ressignações diante de quem amamos, vendo no espelho uma construção política de amor que seja apresentada como a nossa cor - seja lá o que isso quer dizer. A maioria de nós, homens negros, fora destes espaços de debates intelectualizados, destes ambientes de sociabilidade voltados para pessoas negras e de muitos circuitos de discussão política racial. Acredito que a maioria de nós, homens negros, não se importa e não dá a mínima atenção para qualquer discussão sobre emocionalidades, afetuosidades como elementos constitutivos de nossas personalidades sociais. Será que isto é verdade? O que bell hooks nos diz:

Homens negros são vistos como incapazes para articular totalmente e reconhecer a dor das suas vidas. Eles não têm um discurso público nem audiência na sociedade racista que lhes permitam dar voz a sua dor. Infelizmente, os homens negros muitas vezes evocam uma retórica racista que identifica o homem negro como um animal, falando de si mesmos como 'espécies em vias de extinção', como 'primitivos', em sua tentativa de obter o reconhecimento do seu sofrimento (...) Quando os jovens negros adquirem uma poderosa voz e presença pública via produção cultural, como já aconteceu com a explosão da música rap, isso não significa que tenham um veículo que lhes permita articular essa dor (HOOKS, 1992, p. 35). 
Esta última afirmação de bell hooks poderia ser invertida sem perder o seu potencial crítico: foi a música rap que, contemporaneamente, se apresentou como um dos poucos instrumentos públicos por meio do qual esta dor vivida por muitos homens negros urbanos está sendo apresentada, mesmo que esta exposição não traga detalhamentos acerca de certas complexidades psicológica do Eu. Ao nos trazer descrições de contradições vivenciadas em realidades sociais excludentes para homens negros, o rap aponta para um caminho por meio do qual podemos discutir tais dores e sofrimentos, mesmo que não o faça com alguns detalhes necessários.

De fato, ainda não explicitamos no discurso público que o dito privilégio masculino nos isenta de um conjunto de preocupações e problemas relacionados aos afetos e emoções vividos por pessoas com quem temos vínculos diretos, como irmãs e irmãos, mães e pais, companheiras e companheiros de afeto e de desejo, negros e/ou brancos, mesmo em situação de pobreza e exclusão. Embora isto não nos garanta muita coisa, mesmo que "nós" homens negros não estejamos preocupados com muitas fragilidades e sofrimentos sociais vividos por outros grupos de pessoas, precisamos falar de sofrimentos e fragilidades, pois isso se contrapõem aos discursos racistas e sexistas. Em outras palavras, não existe imunidade emocional quando dizemos que somos fortes e resistentes. Ser o "negão", o "cara grande", o "forte", é uma armadilha emocional, pois ela omite e interdita possibilidades de construir vocabulários sobre nossas complexidades existenciais que ainda é limitada por interditos presentes em nós mesmos e que nos impedem de falar sobre nós mesmos. Aquele "isolamento intolerável" decorrente do que Frantz Fanon (0000) chamava de "exacerbação afetiva" é talvez uma das maneiras pelas quais podemos pensar estes modos de subscrição destes tropos do "forte", do "negão", do "quente", do "macho". 2

No mesmo texto de bell hooks citado anteriormente, assinala-se que as dificuldades de falar sobre esta dor (social) diz respeito ao modo como brutalização,

2 Sobre uma dicussão mais apurada acerca da relação entre identidade racial, opressão política e negação da vida cultural como elementos que desenham tramas simbólicas de subjetivação enredadas nas diferentes práticas de inscrição da violência, dentre elas as práticas de violência verbal. Ver: OLIVEIRA, Regina Marques de Souza. FRANTZ FANON, PSICOLOGIA E PSICANÁLISE: EPISTEMOLOGIAS DA VIOLÊNCIA. Revista da Associação Brasileira de Pesquisadores/as Negros/as (ABPN), [S.l.], v. 10, n. 24, p. 40-66, fev. 2018. ISSN 2177-2770. Disponível em: $<$ http://abpnrevista.org.br/revista/index.php/revistaabpn1/article/view/573>. Acesso em: 17 Novembro. 2019. 
virilidade e truculência aparecem como ambivalências complexas nas emocionalidades vivenciadas por muitos homens negros. Em minhas memórias, relembro que minha mãe, corrigindo o "filho malcriado", espancava-me com um grande pedaço de madeira porque eu "aguentava umas pauladas". Eu era "grandão". Ela dizia que, apesar de tudo isso, de toda a violência e brutalização, ela "queria o meu bem". Tive uma namorada que queria que exigia de mim que fosse carinhoso e afetuoso, atenciosos e dedicado, mas viril, forte e incansável durante o ato sexual. Eu também queria isto dela, mas achava que uma coisa não podia estar ao lado da outra. Sentia-me respeitado pelos caras da minha rua porque era "grandão" e "bom de porrada". Porém, quando passei a estudar demais, fui isolado, perdi amigos e deixei de participar das festas e encontros de amigos porque estudava demais. Uma de minhas professoras do ensino médio apreciava a dedicação que eu tinha aos estudos porque era difícil que um cara "como eu" fosse dedicado aos estudos.

A brutalização conduz homens negros à se comportar de modo bronco e inculto e nos leva a subscrever esta conduta de maneira tão sub-reptícia e eficiente, durante tanto tempo, que isto pode nos levar a pensar que precisamos ser uma pessoa bruta e truculenta, mesmo que apenas em situação de conflito, para sermos respeitados. Pensamos que o temor que causamos nas pessoas é respeito. Em certa medida, isto te enche de uma suposta força para si. Mas, em uma medida incerta, haverá um momento em que você percebe que está "colocando para fora" ressentimentos, afastando, amedrontando e confundindo as pessoas que estão perto de você.

Devemos entender que isto foi colocado dentro de nós, não nasceu conosco. A virilidade pode até nos defender daquilo que julgamos como abusos e desrespeitos, pode até fazer com que a gente pense que está se preservando, fazendo com que nos deleitemos sobre nossa suposta capacidade de provocar prazer sexual, mas ela pode te isolar, afastar aqueles que querem fortalecer você e te apoiar como um sujeito que tem mentalidades e corporalidades, não apenas cabeça e corpo. Se você é visto como um sujeito brutalizado, visto como um sujeito truculento, visto como um sujeito viril durante muito tempo, começará a acreditar que não precisa de outras "forças" para ser um sujeito.

Devemos perceber que, no momento em que nossa subjetividade é coisificada, nossas complexidades ontológicas são reduzidas ao simplório estereotipado da 
subordinação política, passamos a pensar sobre nós somente pela perspectiva da marginalização, da violência e da virulência: homens negros passam a ser vistos somente por dentro da hierarquia e da desigualdade. Os modos pelos quais estes corpos são masculinidades e racializadas em suas próprias experiências deixa de importar. Mesmo que sujeitos, a pespectiva da marginalização nos registra como meros predicados. Neste debate sobre desejos, emoções e afetos, um modo de sair deste círculo de reificação no qual as masculinidades negras têm sidos colocadas na história do racismo e do sexismo brasileiro pode estar nas estratégias narrativas tecidas pelos próprios sujeitos que vivenciam estas masculinidades racializadas, podendo ser vistas sob a fragmentação e a contradição:

Devemos fazer a nossa História, buscando nós mesmos, jogando [com o] nosso inconsciente, [com] nossas frustações, [com] nossos complexos, estudando-os, não os enganando. Só assim poderemos nos entender e fazer-nos aceitar como somos, antes de mais nada pretos, brasileiros, sem sermos confundidos com os americanos ou africanos, pois nossa História é outra como é outra nossa problemática (NASCIMENTO apud RATTS, 2007: 97.

Precisamos tensionar uma lógica binária de pensamento que divide o mundo entre maldade e bondade, positivo e negativo, inferior e superior. Se privilégio é não se preocupar e não se responsabilizar por um conjunto de coisas, de modo que este conjunto de coisas passa a não existir para quem vivencia privilégios, então podemos enfrentar esta fronteira: precisamos descobrir o que os privilégios supostamente colocam para fora do discurso, para fora das narrativas conhecidas e dos vocabulários analíticos e políticos que estão sendo (re)produzidos até este momento de nossa história político-intelectual. Que conjunto de práticas existenciais, vivências políticas e processos simbólicos diferentes homens negros podem descrever com detalhes e acuidade porque são construídos socialmente como diferentes homens e negros? Como descrever práticas, vivências e processos que estão fora das preocupações destes homens negros? Como conciliar preocupações e vivências com uma "política da responsabilidade com outros sujeitos"? Eu posso ser responsável pelas pessoas com quem me relaciono afetivamente não porque sou um corpo masculinizado e racializado, mas porque esta responsabilidade me ajuda a enfrentar fantasmas raciais que fazem surgir medos masculinos (e vice-versa) que surgem diante do espelho das 
desigualdades.

Somente podemos sentir a precarização de nossas vidas como homens e negros se acreditarmos que existe apenas a masculinidade patriarcal, heterossexual e branca do mundo perfeito ou talvez existem dilemas que abrigam elementos negativos que as masculinidades negras precisam enfrentar a partir delas mesmas? Masculinidades racializadas devem começar a ser vistas como experiências que articulam em torno dos sujeitos que as vivenciam um conjunto de fragilidades afetivas e de sofrimentos emocionais, uma série de contradições psicológicas e de paradoxos políticos. Masculinidades racializadas não estão acopladas nos corpos de homens negros, pois elas não nascem nestes corpos, são colocadas, forçosamente, nestes corpos.

Para entendermos como homens negros de diferentes orientações sexuais, de diferentes classe sociais, de distintas orientações políticas, são racializados e masculinizados no contexto brasileiro, precisamos decifrar o que temos chamado de masculinidades negras fora de uma leitura dicotômica entre, por um lado, a oposição mente e corpo que retira sofrimentos, sensibilidades, emocionalidades, interesses, intencionalidades e direcionamentos utilitaristas, contradições e paradoxos e, por outro lado, as vivências reais destes diferentes homens negros, deixando de conceber o que é geral no particular, evitando particularizar o que é geral.

Aquilo que Sigmund Freud ([1918] 2006) identificava como sendo um "narcisismo das pequenas diferenças", algo que, talvez, esteja agindo nos correntes processos de diferenciação identitária política, nos mecanismos de construção das narrativas sempre tecidas sobre identidades coletivas racializadas usadas para a afirmação de um sentimento de pertencimento e de solidariedade, talvez implique em uma energia para mover discursivamente atos emocionais para emanação de repulsas sobre a discordância, de culpabilização do outro, de transferências de responsabilidades sobre escolhas e destinos individuais. Em suma, este "narcisismo" talvez ajude a entender um sentimento de estranheza e hostilidade entre sujeitos que "se parecem, mas não são idênticos", bem como perceber alguns processos de isolamento individual que se ocultam sob a aversão a tudo que percebemos como internamente diferente.

Alguns dias atrás estava me perguntando: se na sociedade brasileira homens negros jovens estão morrendo antes mesmo de completar a maturidade, por que esta sociedade precisa prepará-los para lidar com as complexidades da vida social? Se ele 
pode morrer antes dos 30 anos (e/ou matar para não morrer), por que precisa ser educado, escolarizado, sensibilizado, integrado, familiarizado, socializado e amado para uma vida longa? De todo modo, se você chegou até aqui (se é homem negro, está vivo e tem mais de 30 anos) e está lendo este texto confessional, deve estar se perguntando o porquê do título que escolhi. Minha inspiração é o livro sem tradução para o português chamado How to slowly kill yourself and others in America, do escritor negro gay Kiese Laymon (2013), que consiste em um conjunto de textos escritos para mulheres e homens negros, vivos e mortos, familiares e amigos que estiveram e estão na vida de Laymon.

O objetivo do livro de Laymon “(...) não é escrever sobre liberdade, mas falar sobre sobrevivência, benefícios e pesos de ser negro". Este livro tem me inspirado a escrever um livro próprio que consiste em um conjunto de cartas para homens e mulheres negras de minha vida. Neste livro, escreverei para os homens e mulheres negras que estão vivos, considerando-os como se estivessem mortos, advertindo-os sobre como podemos nos manter "vivos" diante das maneiras pelas quais a violência se reinventa entre nós quando tentamos ser pacíficos e respeitosos. Quero escrever como a violência se reintroduz subrepticiamente entre nós quando, sob a vontade de poder nos fortalecer diante das armadilhas do racismo e do adoecimento trazido pela violência racial, talvez nos desumanizemos ao transformar qualquer outro, e qualquer um outro que identifiquemos como um outro, em oposição ao nosso Eu. Para os segundos, os que estão vivos, tentarei explicar como poderíamos fazer de nossas vidas uma passagem melhor, mesmo diante destas violências que quer nos tornar "mortos-vivos". Talvez, pensar masculinidades negras sob a contradição e sob o conflito seja um caminho para sair do binarismo. Quero terminar este texto com uma mensagem ambivalente que recebi tempos atrás de uma mãe-de-santo: “meu filho, teu coração tá na cabeça, tua cabeça tá no teu corpo e o teu corpo tá no teu coração!”

\section{REFERÊNCIAS BIBLIOGRÁFICAS}

CACIOPPO, John; PATRICK, William. Solidão: a natureza humana e a necessidade de vínculo social. São Paulo: Editora Record, 2010.

FREUD, S. "O tabu da virgindade (Contribuições à psicologia do amor III) (1918 [1917]). In: Edição Standard. Vol. XI, Imago: Rio de Janeiro. 1970. 
GILROY, Paul. O Atlântico Negro: modernidade e dupla consciência. São Paulo: Editora 34; Rio de Janeiro: Universidade Cândido Mendes/Centro de Estudos Afro-Asiáticos, 2001

hooks, bell. Black Looks: Race and Representation. Boston: South End Press, 1992.

PACHECO, Ana Cláudia Lemos Mulher negra: afetividade e solidão, EDUFBA, 2013

RATTS, Alex. Eu Sou Atlântica: sobre a trajetória de vida de Beatriz Nascimento. São Paulo: Imprensa Oficial e Instituto Kwanza, 2007.

SPIVAK, Gayatri Chakravorty. Pode o subalterno falar? Belo Horizonte: Editora da UFMG, 2010

OLIVEIRA, Regina Marques de Souza. Frantz Fanon, Psicologia e Psicanálise: epistemologias da violência. Revista da Associação Brasileira de Pesquisadores/as Negros/as, v. 10, n. 24, 2018, p. 40-66.

Recebido em: 30/09/2019

Aceito em: 30/10/2019 